Check for updates

London, UK

Cite this as: BMJ 2021;374:n2221

http://dx.doi.org/10.1136/bmi.n2221

Published: 27 September 2021

\section{Role model: Krishnarajah Nirantharakumar}

\section{Krishnarajah Nirantharakumar talks to Helen Jones about how growing up during the war in Sri Lanka shaped his career and his passion for public health}

\section{Helen Jones}

“A career in medicine was an accident," says Krishnarajah Nirantharakumar, a professor of health data science and public health at the University of Birmingham.

"I was initially drawn to engineering, but my father was a surgeon in a war zone. If there was a bomb blast, then an armoured car would come and take him to the hospital, so I could see the real value of the work."

After studying medicine at the University of Colombo, Nirantharakumar moved to the UK and worked in a number of hospitals before specialising in epidemiology, public health medicine, and health informatics.

"Although my father was a surgeon he spent a lot of time writing books on public health, which inspired me," he explains. "I also liked epidemiology because it's investigative. You feel like Sherlock Holmes as you investigate the reasons for diseases, what treatment works, and the prognosis for patients."

Nirantharakumar combines his interest in epidemiology with health informatics, which he describes as a discipline where three sciences merge.

"Firstly there's data science-how you capture good quality data for specific study designs; secondly is computer science-how you use computational methods and technology; and finally there's health science-where you look at how you can prevent, detect, and manage health conditions better to improve the health of the population."

He works on developing digital tools that expedite healthcare research and is the co-innovator, with his colleague Krishna Gokhale, of DExtER (Data Extractor for Epidemiological Research) an automated platform for extracting data from GP medical records.

Nirantharakumar's interests in computing and academia stem from his experiences growing up in Sri Lanka. "Because of the war and civil unrest, my medical studies were delayed by two years, so I took a diploma in computer science. I could see that computers would play a key role in the future in improving health," he says.

Nirantharakumar is keen to encourage medical students to take up a career in public health, but he does acknowledge that it requires certain skills. "You have to have innate patience because public health measures take time to reap the benefits," he says. "It's all about a long term strategy that has a huge impact." He also adds that those interested in health informatics will need to have "passion, patience, and good maths and computational skills.”
One of his passions is his effort to set up a team in a war affected area of Sri Lanka to help others begin a career in epidemiology and public health. He also works in collaboration with others to lead a global health informatics team to improve the health and wellbeing of disadvantaged communities in low and middle income countries.

\section{Nominated by Joht Singh Chandan}

“In Krishnarajah's (Krish) role as an academic public health consultant his support for his colleagues, and in particular juniors, has been exemplary.

"Krish has a real passion for teaching and supporting the next generation. He has amassed a team consisting of almost 20 junior clinical and non-clinical researchers who he has mentored to find their own path in clinical and public health research. His desire has never been to impose his vision and goals on them, but rather to train them and equip them for their own successes.

“Krish doesn't chase personal success. He dedicates a lot of time working in collaboration with others, supporting their work and research, particularly in low income countries.

"There are many other reasons why I think Krish is a great role model, but in summary, he has a track record of remarkable humility, hard work, genuine support for application) to use skills and resources to do good around the world for health."

Joht Singh Chandan is a National Institute for Health Research academic clinical lecturer in public health at the University of Birmingham. junior colleagues, and a desire (as well as practical 